\title{
Manufacturing and Testing of Light-Weight Foamed Concrete: Experimental Results
}

\author{
Yousef Al-Abdallat ${ }^{1} \&$ Jehad A. A. Yamin ${ }^{1}$ \\ ${ }^{1}$ The University of Jordan, School of Engineering, Industrial Engineering Department, (The National \\ Program For Linkage Academic Institutes With Industrial Sectors "Faculty for Factory" ), Amman 11942, \\ Jordan \\ Correspondence: Yousef Al-Abdallat, The University of Jordan, School of Engineering, Industrial Engineering \\ Department, Amman, 11942, Jordan. E-mail: abdallat@ju.edu.jo
}

Received: December 27, 2018

Accepted: January 8, 2019

Online Published: February 26, 2019

doi:10.5539/mas.v13n3p128

URL: https://doi.org/10.5539/mas.v13n3p128

\begin{abstract}
With human existence, a tremendous number of materials and engineering materials were developed to match the continually changing human needs. Therefore, Lightweight foamed concrete (LFC) materials were fabricated and tested experimentally using locally available feedstock materials to accommodate these changes.

This was done at the University of Jordan's labs at the School of Engineering. The samples were made by varying the percentages of foam and accelerator. The foam used locally was the STAR foam while the calcium chloride. The samples were first machined into cylinders then tested in the School of Engineering Labs for strength, thermal conductivity and absorption. Later on, modeling and optimization of the experiment data was conducted.

It was found that certain samples showed good machinability during forming. Some samples showed excellent behavior from stress point of view, others were good in thermal conductivity and some other samples were good in absorption behavior. Further, no single sample or mixture properties gave the best results.
\end{abstract}

Keywords: foam, absorption, tensile test, thermal conductivity, light weight foam concrete

\section{LIST OF ABBREVIATIONS}

E: Modulus of elasticity.

FC: Foamed Concrete.

$\mathrm{K}$ : Thermal conductivity.

LFC: Lightweight Foamed Concrete.

m: Mass flow rate.

W.A: Water Absorption.

\section{Introduction}

Foam as shown in Figure (1) is a mixture of liquid, chemical additives, and compressed gases. The gaseous phase could be nitrogen, carbon dioxide, natural gas and air. Foam is a multiphase, metastable, compressible fluid, and has a consistency similar to that of shaving cream. Foam is generally divided into two wide categories: foam in bulk and foam in porous media. 


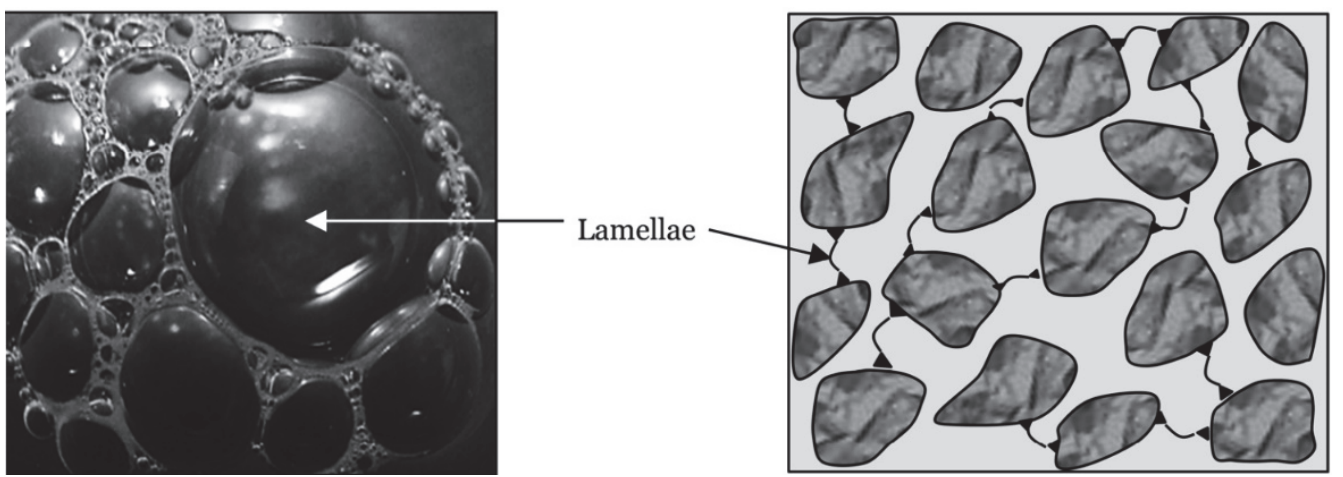

Figure 1. (a) Foam in bulk that is encountered in everyday life. (b) Foam in porous media. Lamellae are thin liquid films with a thickness of the order of 10-100 nm

In foam in bulk, the size of a container is much larger than individual bubbles, whereas in foam in porous media, the diameter of bubbles is comparable to or larger than the pore size (Prud'homme, 2017).

According to Hirasaki (Bertin et al., 1998), foam in porous media is defined as a dispersion of gas in a liquid such that the liquid phase is continuous, and at least some part of the gas is made discontinuous by thin liquid films called lamellae. The lamellae are stabilized by the presence of surfactant in the liquid phase.

The lamellae (of the order of 10-100 nm thick) are stabilized by surfactants adsorbed at the gas/liquid interface (Harozov, 2008).

Foam has many uses in diversity of applications, here are some of them: Isolation applications, Fire-fighting extinguisher, Car seat, truck seat and boat seat, Lubricant for drilling processes.

Foamed concrete is a versatile material which has become widely used in the construction industry; in roof slopes, floor leveling and insulating layers of wall constructions, as well as for any kind of void filling (mines, tunnels, road basements, ground stabilization, and others), owing to its free-flowing properties, excellent heat-insulating characteristics, low density and affordable strength values (Tarasov et al., 2010).

Properties of foam concrete could be classified into three categories, found in Table (1).

Concrete is a well-known construction material that has been used in construction industry since its invention. There is a common mistake that concrete is synonyms to cement but it is not. Concrete is a weighted mixture of the following substances: cement, water and aggregate.

In recent years, the construction industry has shown significant interest in the use of Lightweight Foamed Concrete (LFC) as a building material.

Table (1). Properties of Foam Concrete

\begin{tabular}{lll}
\hline Fresh state properties & Physical properties & Mechanical properties \\
\hline 1. Consistency & 1. Drying shrinkage & 1. Compressive strength \\
2. Stability & 2. Air-void systems & 2. Flexural and tensile strengths \\
& 3. Density & 3. Modulus of elasticity \\
\hline
\end{tabular}

LFC was used a century ago, in precast applications in 1923. It has been adopted in Europe in the early 1980s, since then an accelerated deployment of LFC began to spread all over Europe.

LFC is known also as "Foamed Concrete" which is a light weight material could be formed by creating small bubbles in concrete mixture by mechanical or chemical methods. It is characterized by its light weight, ease of fabrication, durability and low cost which are all attractive for engineers.

LFC consists of Portland cement (black cement), water, foam (a mixture of liquid, chemical additives, and compressed gases) and an accelerator (a substance that would rapidly accelerate the solidification process, in this case; Calcium Chloride).

In 1987 a full-scale assessment on the application of LFC as a trench reinstatement was carried out in the United 
Kingdom and the achievement of this trial led to the extensive application of LFC for trench reinstatement and other applications followed (Mydin et al., 2014).

Apart from the density of the aggregates, the density of the concrete also depends on the grading of the aggregates, their moisture content, mix proportions, cement content, water to binder ratio, and chemical and mineral admixtures. Besides characteristics of the materials, it also depends upon the method of mixing, compaction, and curing condition (Ünal et al., 2007).

(Barnes, 2008) reported that there is a correlation between the density and compressive strength of foamed concrete. Comparing the wet density of the foamed concrete at the point of discharge, with the wet density determined during development testing gives an estimate of likely strength at a given age.

The cellular structure of foamed concrete contributes to good thermal insulating properties and low thermal conductivity values.

(Sari et al., 2017) showed that the thermal conductivity of foamed concrete ranges between $0.1 \mathrm{~W} / \mathrm{mK}$ and 0.7 $\mathrm{W} / \mathrm{mK}$ for dry densities of $600 \mathrm{~kg} / \mathrm{m} 3$ to $1600 \mathrm{~kg} / \mathrm{m}^{3}$. These thermal conductivities of foamed concrete are typically $5 \%$ to $30 \%$ of those measured on normal weight concrete. Thermal conductivities reduce with decreasing densities.

Foamed concrete depends on its many characteristics for its different applications in building construction. These are some guidelines on production and processes to produce the best foamed concrete.

The strength of foamed concrete are increase by:

decreasing porosity (less foam),

(ii) using finer sand, less than $5 \mathrm{~mm}$,

(iii) introducing small air bubbles (between $0.1 \mathrm{~mm}$ and $1.5 \mathrm{~mm}$ ) with uniform distribution

(iv) using fly ash and silica fume for pozolanic reaction,

(v) air curing (compared to sealed/ water curing), and

(vi) usage of polypropylene.

The main objectives of this study are:

1. To experimentally study and quantify mechanical and thermal properties of LFC.

2. To test and characterize the mechanical and thermal properties of proposed LFC.

3. To determine the absorption of lightweight foamed concrete with different percentage of Foam and Calcium Chloride.

\section{Methodology and Experiment}

To achieve research goals and objectives, a data acquisition stage started from preparing the samples to be tested to finally test them using several types of tests and obtain the required data as illustrated in the figure (2) below. 


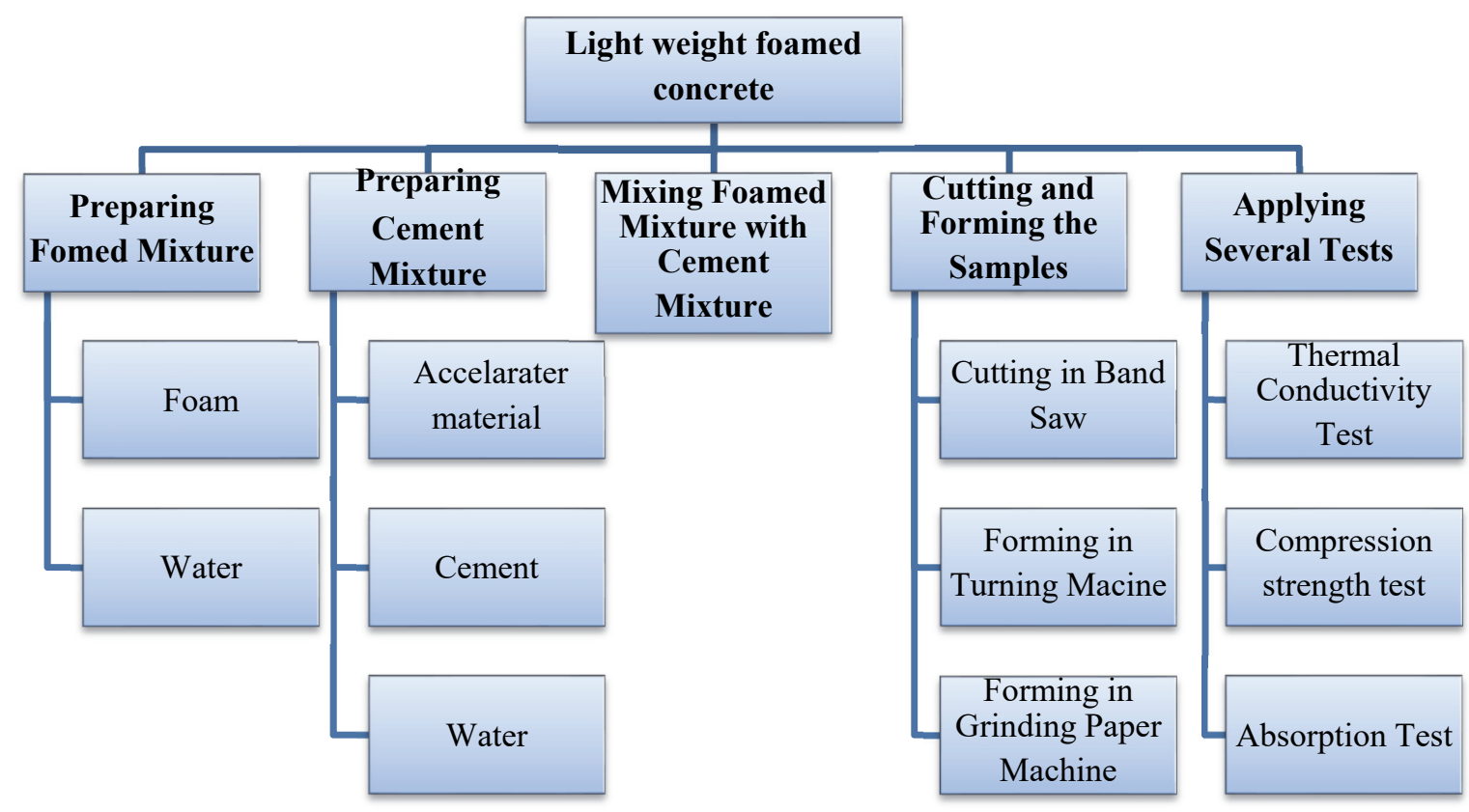

Figure (2). Work breakdown structure Data Acquisition Stage

\subsection{Equipment}

1) Graduated Cylinder a shown in figure (3): to calibrate the amount of water and foam, where the proportion of water to foam is $10 \mathrm{~L}$ to $0.2 \mathrm{~L}$ respectively.

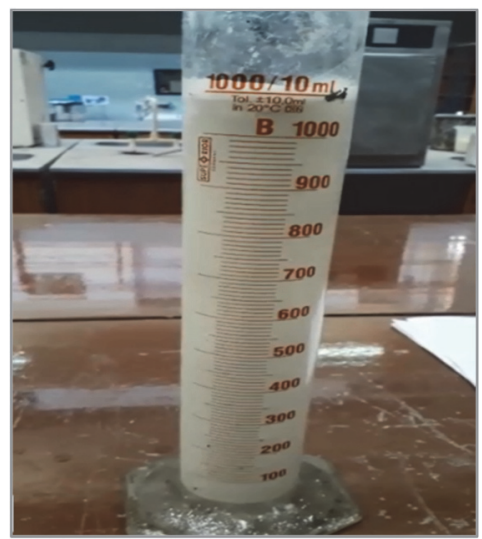

Figure (3). Graduated Cylinder.

2) Foam generator: to mix up water and foam homogenously under high pressure air "10pa, 2.2bar".

4) Turning machine shown in figure (4): to roll the specimen into cylindrical shape to meet the specifications for testing machines.

There are two types used, 4 jaw chucks to hold cubic sample "see figure (b)", and 3 jaw chucks to hold cylindrical sample "see figure (c)". 


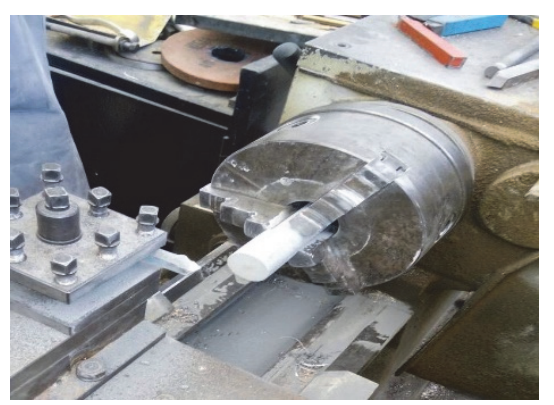

Figure (4). Turning Machine

5) Vernier Caliper: is a device that lets the user measure more precisely than could be done unaided when reading a uniformly divided straight or circular measurement scale.

6) Grinding paper machine: is a type of machining using an abrasive wheel as the cutting tool. Each grain of abrasive on the wheel's surface cuts a small chip from the work piece via shear deformation.

7) Hydraulic universal material tester shown in figure (5), $50 \mathrm{kN}$ : to measure the maximum compressive strength that the specimen can sustain without failure. Strain rate for this machine is very small and equal to $5 \mathrm{~mm} / \mathrm{min}$.

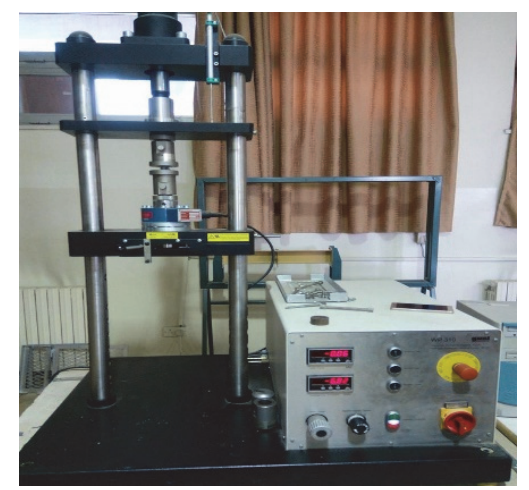

Figure (5). Hydraulic Universal Material Tester

8) Thermal conductivity apparatus shown in figure (6): to measure thermal conductivity of the sample.

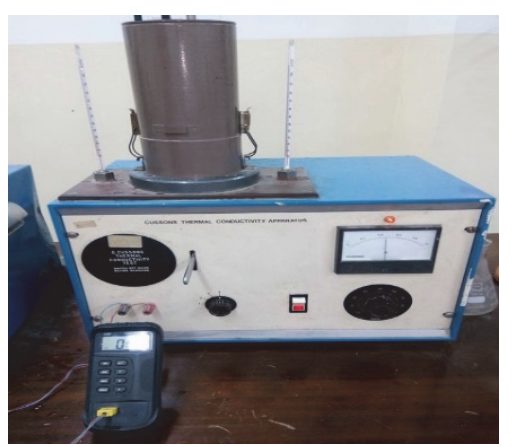

Figure (6). Thermal Conductivity Apparatus

\subsection{Materials}

The main materials used in this project are:

1) Portland Cement (Black cement): is the most common type of cement in general use around the world, used as a basic ingredient of concrete.

2) Liquid Foam: star concrete foam

3) Accelerator Material 
Several chemicals are known to act as accelerators for concrete - calcium format, aluminum chloride, potassium carbonate, sodium chloride and calcium chloride (among others) - but calcium chloride is most widely used. Its popularity is due to its ready availability, low cost, predictable performance characteristics, and successful application over several decades.

Concrete has to satisfy many performance requirements. The addition of calcium chloride promotes certain desirable properties and affects others; but the performance of a concrete containing calcium chloride admixture can reasonably be predicted only when both the short- and long-range effects have been established. Such knowledge permits judicious use of admixtures. Originally, the science of admixture was the province of a specialist, but with advanced building technology and ever increasing new demands on builder, engineer and architect it is necessary that all involved in building have as much knowledge of admixtures and their effects as of cement, aggregate or the mixing water.

\subsection{Thermal Conductivity Test}

Thermal conductivity test should be performed for insulation materials from 3 to 4 hours using thermal conductivity apparatus. Specimen specifications should be $2.5 \mathrm{~cm}$ in diameter and $10 \mathrm{~cm}$ in length. There are two classes of methods exist to measure the thermal conductivity of a sample: steady state and non-steady state (transient method). This research has studied steady state method. In general, steady state method performs a measurement when a temperature of the material doesn't change with time. This makes the signal analysis straight forward (steady state implies constant signals). Bear in mind that a well-engineered experimental setup is usually needed. The analysis of specific thermal conductivity value is as follows:

$$
K=J * \dot{m} * L *(T 2-T 1) /(A *(T 4-T 3))
$$

Where,

J: a constant equals to $4168(\mathrm{~J} / \mathrm{kg}-\mathrm{K})$

m: mass flow rate $(\mathrm{kg} / \mathrm{s})$

L: length of the sample $(\mathrm{m})$

A: area of the sample $\left(\mathrm{m}^{2}\right)$

The mass flow rate was measured by the level of water flow from thermal conductivity apparatus to outer cylinder, each grade represents one gram, for a specific time. The cross section of the samples is circle.

\subsection{Compressive Strength Test}

Out of many test applied to the concrete, this is the utmost important which gives an idea about all the characteristics of concrete. By this single test one judge that whether Concreting has been done properly or not. Compressive strength of concrete depends on water-cement ratio. Compressive strength Test is carried by cube with specification of $1.5 * 1.5 * 1.5 \mathrm{~cm}$. This test is used after 7 days curing in order to achieve $65 \%$ strength.

The compressive strength test was conducted by using (Hydraulic universal material tester, $50 \mathrm{kN}$ ), constant axial loading rate $5 \mathrm{~mm} / \mathrm{min}$ was applied on the cubic specimen with dimension of $1.5 * 1.5 * 1.5 \mathrm{~cm}$. The test specimen was located at the center of testing machine plat form. The test was then started at specified loading rate until the test specimen failed and cracks appear on the specimen surface. The maximum load of the test specimen was record in order to calculate the compressive strength. The test results is shown below in figure (7)

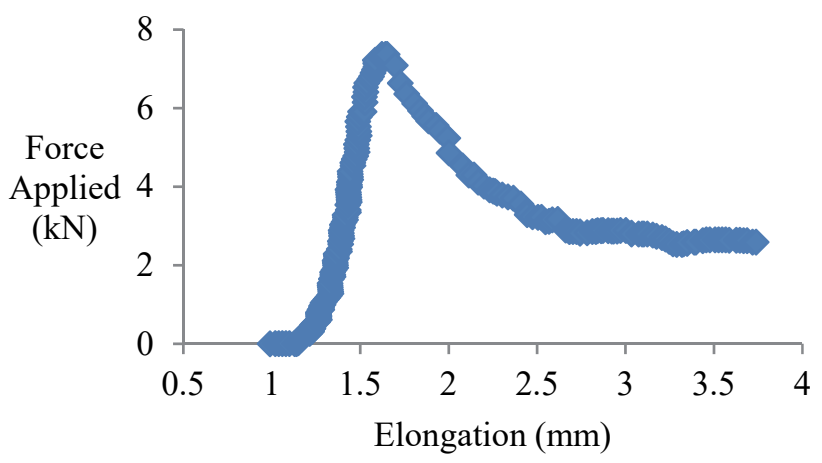

Figure (7). Max Force with Displacement for sample 11 
Compressive strength and strain of the test specimen was calculated by using equations:

$$
\mathrm{F}=\mathrm{P} / \mathrm{A}
$$

Where,

$\mathrm{F}=$ Compressive strength, $\mathrm{MPa}$,

$\mathrm{P}=$ Max load sustained by specimen, $\mathrm{kN}$,

$\mathrm{A}=$ Cross-sectional area of specimen which load applied $\left(\mathrm{mm}^{2}\right)$

$$
\text { Strain }=(\mathrm{Lf}-\mathrm{Li}) / \mathrm{Li}
$$

\subsection{Absorption Test}

Water absorption test was carried out in this study to calculate the water absorption capacity of LFC, prior to the testing, the specimen cubes where taken out one day in advanced from the curing tank. The specimen was wiped to surface dry condition and weighted to obtain dry weight.

$$
\text { W.A }=(\text { Wwet }- \text { Wdry }) / \text { Wdry } * 100 \%
$$

Where,

$$
\begin{aligned}
& \text { W.A = water absorption of LFC, }(\mathrm{g}) \\
& \mathrm{W}_{\text {wet }}=\text { wet weight of specimen, }(\mathrm{g}) \\
& \mathrm{W}_{\text {dry }}=\text { dried weight of specimen, }(\mathrm{g})
\end{aligned}
$$

\section{Results and Discussion}

A total of 20 experiments were conducted resulting in 40 samples. Several factors have been changed while making the samples e.g. the percentages of both foam and accelerator material. Out of the 40, only 11 samples were successful. These samples are shown in Table (1) below.

Table (1). Samples used in the study

\begin{tabular}{ccccc}
\hline $\begin{array}{c}\text { Sample } \\
\text { No. }\end{array}$ & $\begin{array}{c}\text { Foam } \\
\%\end{array}$ & $\begin{array}{c}\text { Cement } \\
\mathrm{kg}\end{array}$ & $\begin{array}{c}\text { Water } \\
\mathrm{ml}\end{array}$ & $\begin{array}{c}\text { Accelerator } \\
\mathrm{g}\end{array}$ \\
\hline 1 & 0.75 & 1.5 & 500 & 20 \\
2 & 0.85 & 1.5 & 500 & 20 \\
3 & 0.5 & 1.5 & 500 & 10 \\
4 & 0.5 & 1.5 & 500 & 10 \\
5 & 0.5 & 1.5 & 500 & 0 \\
6 & 0.75 & 1.5 & 500 & 10 \\
7 & 0.75 & 1.5 & 500 & 10 \\
8 & 0.75 & 1.5 & 500 & 0 \\
9 & 0.25 & 1.5 & 750 & 15 \\
10 & 0.75 & 1 & 500 & 15 \\
11 & 0.25 & 1.5 & 750 & 10 \\
\hline
\end{tabular}

\subsection{Thermal Conductivity Test.}

Thermal conductivity results are shown in Figure (8). As can be seen from this figure, sample 7 has the lowest thermal conductivity $(\mathrm{K})$ value which means largest thermal insulation. The range of $\mathrm{K}$ based on results is between $(0.83-3.5) \mathrm{W} / \mathrm{m} . \mathrm{K}$. There is no clear pattern for the effect of variables on this property. This necessitates the use of correlation factors to study the effect. The maximum change of thermal conductivity (within the range studied) is $76.28 \%$. 


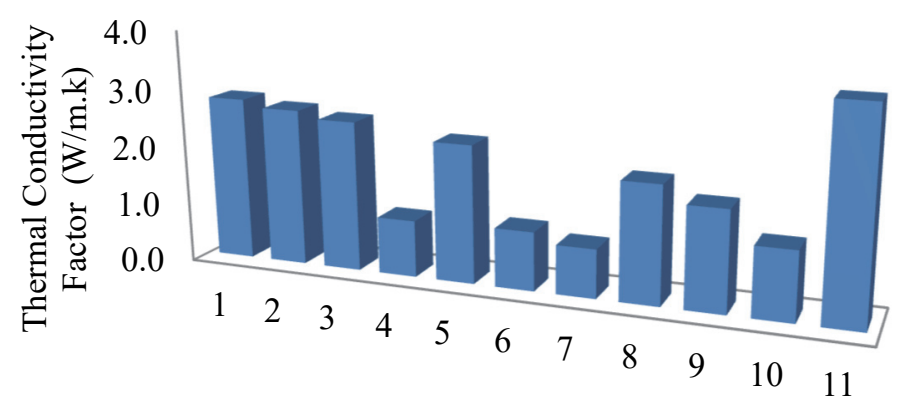

Samples No.

Figure (8). Thermal Conductivity Measurements

\subsection{Compressive Strength Test}

The compressive properties of the Foamed Concrete e.g. maximum yield stress and strain were measured experimentally using the Hydraulic Universal Material Tester. The results are shown in Figures (9 and 10). It is worth mentioning that the yield stress must be maximized for good performance at lower strain rates.

Referring to Figure (9) sample 11 has the highest value of yield stress, which means that it gives the highest compressive strength. The compressive stress ranged in between $(355.5556-32,755.56) \mathrm{kPa}$.

Further noticed, there are samples that show the poorest yield stress behavior e.g. 2, 4, 8 and 10. These samples need further analysis for selection.

Strain rate of the tested samples are shown in Figure (10). Strain is a measure of ductility; it shows how the material expands or contracts relative to its instantaneous dimension. Specimen 4 records the highest strain rate which equals to 41.176. The range of strain based on results is in between (1.45-41.176). Depending on the nature of application of the Foamed Concrete, this value must either be maximized for good energy absorption or minimized for space limitations.

Most of the samples studied showed lower strain rates, which are good as insulation materials given the space limitations). Others showed good strain behaviors which are good as energy absorption materials.

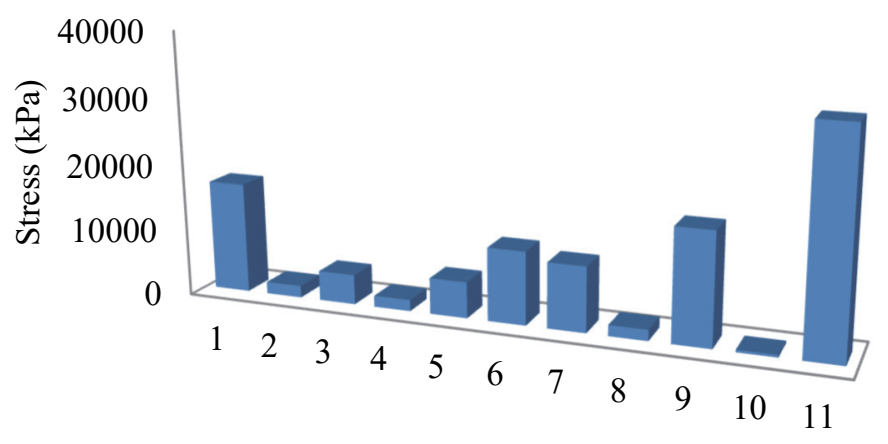

Samples No.

Figure (9). Max Stress Measurements 


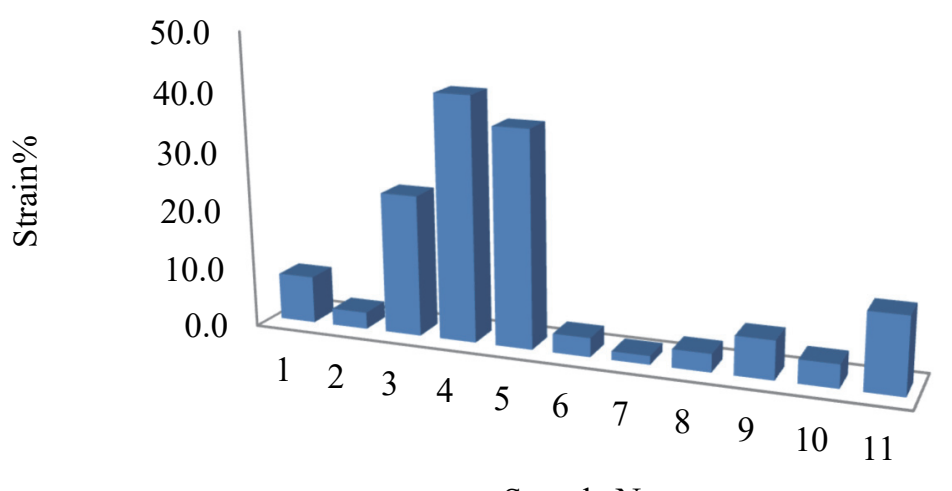

Sample No.

Figure (10). Maximum Strain Measurement

\subsection{Absorption Test}

Absorption test identifies the amount of water the sample can absorb. This property must be minimized. The results of this section are shown in Figure (11). As shown in figure (11), sample 5 has the lowest value of absorption, which means that it gives the best performance from water absorption prospective. The range of absorption based on these results is in between (1.98-95.27) \%.

It is further noticed that sample 11 gave descent absorption behavior along with other previously discussed tests. This makes it potential candidate for good material.

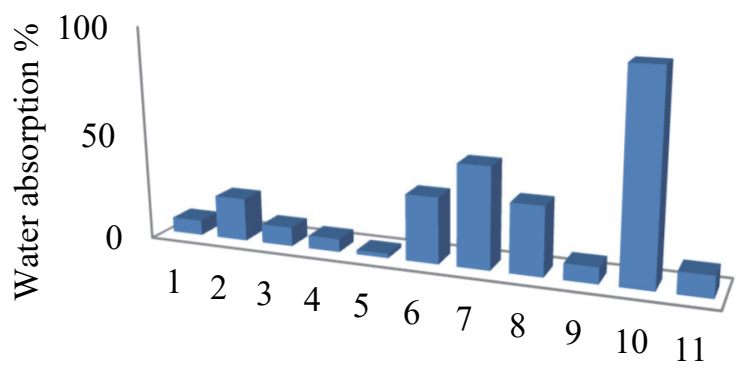

Samples No.

Figure (11). Absorption Percentages (\%)

To find the material that gives the lowest absorption behavior, we need to do modeling and optimization. This will be discussed in the coming sections.

\subsection{Density Test}

Density test indicates how heavy the Foamed Concrete material will be. This should be minimized to lower the load over the building structure.

As shown in figure (12) sample 10 has the lowest value of density which means that would be efficient in terms of weight for LFC applications. The range of density based on results is between (503-1695) kg/m3. Sample 11 also shows promising qualities. 


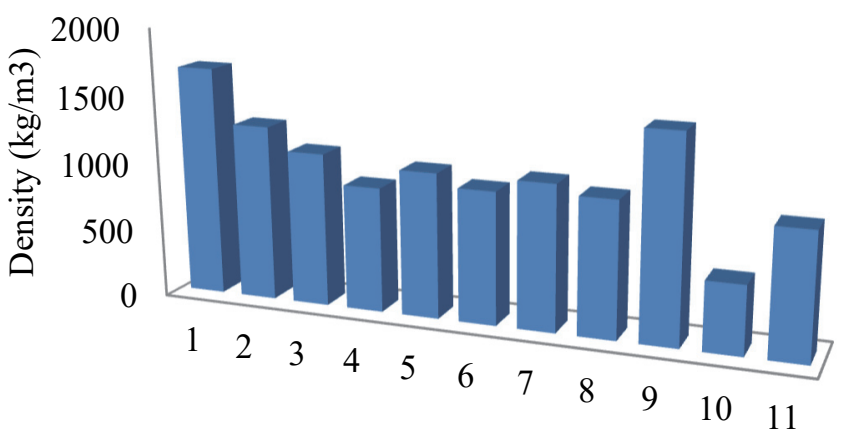

Samples No.

Figure (12). Density Records

To conclude the experimental results, it can be noticed that there were no sample that gave the best performance from all prospective. This necessitated the use of mathematical formulations to help better understanding on how the factors are correlated.

This was done using two different approaches. The first was correlation matrix and the second was the Genetic Programming modeling and optimization.

\subsection{Correlation}

The correlation factor shows the strength of relationship between the inputs and outputs, in this case nine variables were under consideration. The correlation factor also shows how the results are affected by each specified factor. Table (2) exhibits these relations in the shape of matrix in more details.

To locate the correlation for any pair of variables find the value in the table for the raw and the column intersection for those two variables. For example, and according to the table above, there is a strong relationship between the maximum stress and amount of water added.

Table (2). Correlation Matrix

\begin{tabular}{|c|c|c|c|c|c|c|c|c|c|}
\hline & Foam $\%$ & Cement (kg) & $\begin{array}{l}\text { Water } \\
(\mathrm{ml})\end{array}$ & $\begin{array}{l}\text { Accelerator } \\
\qquad(\mathrm{g})\end{array}$ & $\begin{array}{c}\text { Thermal Conductivity } \\
\text { (W/m.K) }\end{array}$ & $\begin{array}{l}\text { Density } \\
\left(\mathrm{kg} / \mathrm{m}^{3}\right)\end{array}$ & $\begin{array}{c}\text { Max Stress } \\
\left(\mathrm{kN} / \mathrm{m}^{2}\right)\end{array}$ & Max Strain & $\begin{array}{c}\text { Absorption } \\
\%\end{array}$ \\
\hline Foam $\%$ & 1 & & & & & & & & \\
\hline Cement & -0.234 & 1 & & & & & & & \\
\hline Water (ml) & -0.815 & 0.149 & 1 & & & & & & \\
\hline Accelerator & 0.1774 & -0.204 & 0.118 & 1 & & & & & \\
\hline Thermal & -0.300 & 0.293 & 0.355 & 0.1045 & 1 & & & & \\
\hline \multicolumn{10}{|l|}{ Conductivity } \\
\hline Density & -0.072 & 0.623 & 0.175 & 0.3945 & 0.3790 & 1 & & & \\
\hline Max Stress & -0.585 & 0.304 & 0.782 & 0.1641 & 0.4898 & 0.2891 & 1 & & \\
\hline Max strain & -0.437 & 0.211 & -0.115 & -0.3851 & 0.0535 & -0.112 & -0.168 & 1 & \\
\hline Absorption & 0.498 & -0.858 & -0.278 & 0.1109 & -0.5016 & -0.648 & -0.346 & -0.513 & 1 \\
\hline
\end{tabular}

Referring to the table above Table the following can be noticed:

The compressive stress is strongly proportional to the water percentage used; this could be concluded from the value of correlation factor $(\mathrm{r}=0.78)$. This behavior is justified by increasing the bonds strength in cement, which are dependent on water availability.

Thermal conductivity is also positively affected by the amount of water, this is clear by the correlation coefficient $(\mathrm{r}=0.35)$, which means it increases with the increase of water and Vice versa. This property must be minimized for good thermal insulation. This requires that the percentage of water must be reduced.

In Addition to water amount, thermal conductivity was found to decrease with increasing the foam percentages, 
which is very desirable in this study $(\mathrm{r}=-0.3)$.

The density is proportional to the cement percentage used. This is clear from the correlation table which shows ( $\mathrm{r}$ $=0.62$ ). To reduce the weight of the foamed concrete, this property must be decreased.

Density was found to decrease with the increase of foam. This is shown by the correlation factor $(r=-0.07)$.

This means that, in order to have a lighter foamed concrete, the cement percentage must be decreased while that of the foam must increase.

Strain is strongly affected by cement amount, where it increases as cement amount increases. This is undesired behavior of the foamed concrete material. This is shown by $(\mathrm{r}=0.2)$. However, as foam increases, the strain rate decreases according to $(r=-0.43)$.

Regarding absorption, the lower the absorption, the better the foamed concrete behavior. This property must be minimized. This could be achieved by increasing the amount of cement $(\mathrm{r}=-0.85)$. On the other hand, higher the foam percentage, higher will be the absorption rate. This is shown by $(\mathrm{r}=0.49)$. This is undesirable characteristic.

It is worth mentioning that the accelerator effect is solely to minimize the solidification time.

\section{Conclusions}

From the above discussion, it can be concluded that:

1. The compressive stress is strongly proportional to the water percentage used.

2. Thermal conductivity is also positively affected by the amount of water.

3. Thermal conductivity decreases with increasing the foam percentages.

4. The density is proportional to the cement percentage used.

5. Strain is strongly affected by cement and foam percent.

6. No single mixture gave the best behavior from all points studied.

7. Samples 5, 10 and 11 are worth studying.

8. The mixture was filled in the molds but another issue was found, the leakage of these molds was solved by adding solid lubricant.

9. A difficulty was faced when separating the sample from the mold, to overcome such one, a liquid lubricant (oil) had been applied to the molds before filling the mixture in it.

10. A difficulty in evacuating the foam generator tank after filling it, so another trail was performed without adding the accelerator to the foam mixture. It has only been added to the water separately.

11. Even with lack of experience and sufficient background of the staff, and equipment and apparatus weren't enough to conduct the experiment properly, an improvement in staff skills was observed that lead to enhancing its learning curves.

\section{References}

Barnes, R. A. (2008). Foamed concrete: application and specification. Excellence in Concrete Construction through Innovation, Proceedings, Kingston-upon-Thames, GB, 9-10 Sep, 2008.

Bertin, H. J., Quintard, M. Y., \& Castanier, L. M. (1998). Development of a bubble-population correlation for foam-flow modeling in porous media. SPE Journal, 3(04), 356-362. https://doi.org/10.2118/52596-PA

Horozov, T. S. (2008). Foams and foam films stabilised by solid particles. Current Opinion in Colloid \& Interface Science, 13(3), 134-140.

Mydin, M. O., Rozlan, N. A., Sani, N. M., \& Ganesan, S. (2014). Analysis of Micro-Morphology, Thermal Conductivity, Thermal Diffusivity and Specific Heat Capacity of Coconut Fibre Reinforced Foamed Concrete. In MATEC Web of Conferences (Vol. 17, p. 01020). EDP Sciences. https://doi.org/10.1051/matecconf/20141701020

Prud'homme, R. K. (2017). Foams: Theory: Measurements: Applications. Routledge. Retrieved from https://onlinelibrary.wiley.com/doi/abs/10.1002/food.19970410116

Sari, K. A. M., \& Sani, A. R. M. (2017). Applications of Foamed Lightweight Concrete. In MATEC Web of Conferences (Vol. 97, p. 01097). EDP Sciences. https://doi.org/10.1051/matecconf/20179701097

Tarasov, A. S., Kearsley, E. P., Kolomatskiy, A. S., \& Mostert, H. F. (2010). Heat evolution due to cement hydration 
in foamed concrete. Magazine of concrete research, 62(12), 895-906. https://doi.org/10.1680/macr.2010.62.12.895

Ünal, O., Uygunoğlu, T., \& Yildiz, A. (2007). Investigation of properties of low-strength lightweight concrete for thermal insulation. Building and Environment, 42(2), 584-590. https://doi.org/10.1016/j.buildenv.2005.09.024

\section{Copyrights}

Copyright for this article is retained by the author(s), with first publication rights granted to the journal.

This is an open-access article distributed under the terms and conditions of the Creative Commons Attribution license (http://creativecommons.org/licenses/by/4.0/). 